University of South Carolina

Scholar Commons

$1-1991$

\title{
A Monte Carlo Study of Rainfall Sampling Effect on a Distributed Catchment Model
}

\author{
Witold F. Krajewski \\ Venkataraman Lakshmi \\ University of South Carolina - Columbia, vlakshmi@geol.sc.edu \\ Konstantine P. Georgakakos \\ Subhash C. Jain
}

Follow this and additional works at: https://scholarcommons.sc.edu/geol_facpub

Part of the Earth Sciences Commons

\section{Publication Info}

Published in Water Resources Research, Volume 27, Issue 1, 1991, pages 119-128.

Krajewski, W. F., Lakshmi, V., Georgakakos, K. P., \& Jain, S. C. (1991). A Monte Carlo study of rainfall sampling effect on a distributed catchment model. Water Resources Research, 27 (1), 119-128. (C) Water Resources Research 1991, American Geophysical Union

This Article is brought to you by the Earth, Ocean and Environment, School of the at Scholar Commons. It has been accepted for inclusion in Faculty Publications by an authorized administrator of Scholar Commons. For more information, please contact digres@mailbox.sc.edu. 


\title{
A Monte Carlo Study of Rainfall Sampling Effect on a Distributed Catchment Model
}

\author{
Witold F. Krajewski, Venkataraman Lakshmi, Konstantine P. Georgakakos, \\ AND SUBHASH C. JAIN \\ Department of Civil and Environmental Engineering and Iowa Institute of Hydraulic Research, University of Iowa, Iowa City
}

\begin{abstract}
A Monte Carlo study of a physically based distributed-parameter hydrologic model is described. The catchment model simulates overland flow and streamflow, and it is based on the kinematic wave concept. Soil Conservation Service curves are used to model rainfall excess within the basin. The model was applied to the Raiston Creek watershed, a small $\left(7.5 \mathrm{~km}^{2}\right)$ rural catchment in eastern Iowa. Sensitivity of the model response with respect to rainfall-input spatial and temporal sampling density was investigated. The input data were generated by a space-time stochastic model of rainfall. The generated rainfall fields were sampled by the varied-density synthetic rain gauge networks. The basin response, based on 5-min increment input data from a network of high density with about 1 gauge per $0.1 \mathrm{~km}^{2}$, was assumed to be the "ground truth," and other results were compared against it. Included in the study was also a simple lumped parameter model based on the unit hydrograph concept. Results were interpreted in terms of hydrograph characteristics such as peak magnitude, time-to-peak, and total runoff volume. The results indicate higher sensitivity of basin response with respect to the temporal resolution than to the spatial resolution of the rainfall data. Also, the frequency analysis of the flood peaks shows severe underestimation by the lumped model. This may have implications for the design of hydraulic structu-es.
\end{abstract}

\section{INTRODUCTION}

Recent technological advances in remote sensing, geographic information systems, and computers make the use of distributed hydrologic models an attractive alternative for flow simulation and flood prediction. The major areas of application of distributed models are, according to Beven and $O^{\prime}$ Connell [1982], forecasting effects of land use change, forecasting the effects of spatially variable inputs and outputs, forecasting movements of pollutants and sediments, and forecasting the hydrological response of an ungaged catchment. The main advantages possessed by a distributed model rest on the spatially distributed nature of its inputs and its use of physically based parameter values measurable in the field; with a distributed model one can measure the effect of changes in the physical parameters on the hydrological response on the whole or part of the catchment [Beven, 1985]. The traditional approach of lumped models, until recently the only one feasible to use in an operational environment, suffers from the inability to properly account for inhomogeneities in basin characteristics and model inputs. The distributed approach can, by definition, represent the basins and the hydrologic processes following the variability of the relevant parameters at a subbasin scale. The distributed models are still in very limited use mainly due to their demands for high computational power and long time required for their setup for a particular basin. Both problems are becoming less and less constraining as new generations of inexpensive but powerful workstations are more and more popular, and the high-resolution data of topography, geology, land cover, and land use are easily manageable using the sophisticated data bases and geographic information systems. Also, the problem of low spatial and temporal resolution of rainfall input is, or will be soon, much im-

Copyright 1991 by the American Geophysical Union.

Paper number 90WR01977.

0043-1397/91/90WR-01977\$05.00 proved with the installation of telemetric gages and radar networks in many countries. England [Collinge and Kirby, 1986] and Japan [Ishizaki et al., 1989] already enjoy such operational networks; in the United States the powerful NEXRAD system [Hudlow, 1988] is just around the comer. Similar developments are also in progress in other European countries.

However, before the distributed hydrologic models are in widespread use, several important questions remain to be answered. The issues of appropriate scales, both temporal and spatial [Wood et al., 1988], choice of models to represent particular physical processes, and assimilation of remotely sensed data need to be investigated. Also, the very practical question of how much is there to be gained from the use of distributed models and under what circumstances has no clear answer. An interesting discussion of many problems associated with distributed models and their application to solve various hydrologic problems is given by Beven [1989].

The objective of this paper is a Monte Carlo investigation of the sensitivity of a distributed physically based hydraulictype hydrologic model with respect to rain gauge sampled rainfall input. In addition, a comparison of the distributed model with a lumped model was performed and is discussed. The small, mixed urban and agricultural basin of Ralston Creek near Iowa City, Iowa, served as the application object for study.

The selected model is based on the well-known kinematic wave theory [e.g., Wooding, 1965]. This approach has been used many times to study various hydrologic problems. Works by Kibler and Woolhiser [1970], Rose et al. [1983], Moore [1985], Moore and Kinnell [1987], Field and Williams [1987], Sunada and Hong [1988], Takasao and Shiiba [1988], and Woolhiser and Goodrich [1988] offer only a few recent examples of such investigations. The original version of the model used in this study was developed by Jain et al. [1982] to study the effects of land use changes on sediment transport and outflow flood hydrograph in the Ralston Creek 
basin. Its satisfactory application to hydrograph simulation has been described by Kumar and Jain [1982].

There are several reasons for choosing a Monte Carlo setup as opposed to using field data. Perhaps the most important one in our case was the lack of a long enough record containing all the information required by the model. Only a few events were documented for the basin, and these were used in model calibration and previous tests [see Kumar and Jain, 1982; Lakshmi, 1989]. However, Monte Carlo simulation is also appealing because it offers a convenient way of performing sensitivity analysis, since the "ground truth" can be assumed as known. The results from a Monte Carlo experiment are statistically valid since long records of data can be generated. The conclusions can be conveniently linked to the parameters used in the simulations. In the case of using field data, the number of storm cases that could be examined is limited, and therefore any general conclusions have to be treated with caution. Another yet important advantage of a Monte Carlo simulation is the ease of simulating the effects of uncertainties due to measurement errors, something clearly impossible with real data. The Monte Carlo simulation approach has been used in a number of recent studies on distributed modeling. For some examples, see Binley et al. [1989a, b], Sharma et al. [1987], and Smith and Herbert [1979].

In order to generate the input rainfall data needed to drive the distributed model, a stochastic space-time rainfall model proposed by Waymire et al. [1984], often referred to as the WGR model, was used. The generated rainfall was then sampled by an imaginary network of rain gauges. The same input was fed into a simple spatially lumped model based on the unit hydrograph theory, and the results of repetitive simulations were analyzed.

The problem of influence of the spatial variability of rainfall on storm runoff has been addressed by several investigators, including Dawdy and Bergmann [1969], Troutman [1983], and Wilson et al. [1979] among others. The study described in this paper is reminiscent of that by Wilson et al. [1979]. Although the overall philosophy of the experiment is quite similar, there are significant differences between the two studies. First, the study described herein is much more detailed in several aspects. Ralston Creek basin, which is about 8 times smaller than the basin used by Wilson et al., has been divided into about 280 segments, as opposed to 21 subcatchments in Wilson's study. This translates to about 100 times increased resolution. Second, the generated rainfall has been sampled at three different network densities, and the temporal aspect of the sampling has been included. The results and corresponding conclusions were obtained in a Monte Carlo framework which makes them more reliable. In the study by Wilson et al. [1979], only two spatial sampling schemes were investigated for a limited number of storms. Another significant difference is in the generated rainfall regime, which in our case is of convective nature, as opposed to the more stratiform rainfall generated by the model of Bras and Rodriguez-Iturbe [1976] that is used by Wilson et al. [1979]. Also, a simple lumped parameter type model was included in our study for comparison.

At this point the authors would like to emphasize that, as in the study by Wilson et al. [1979], the objective was not to model a particular basin but to use a realistic set of physiographic characteristics to study the effects of spatial sampling of rainfall on the prediction of the basin's response.
However, the model performs satisfactorily with real data, as was demonstrated by the verification results of the earlier studies by Kumar and Jain [1982] and Lakshmi [1989].

The components of the distributed model are briefly described in section 2 , and the scenarios investigated within the numerical simulation experiment are discussed in section 3 together with the comparison criteria adopted for the analysis of the results. In section 4 the main results are presented. Conclusions are given in section 5 .

\section{Catchment Model}

\subsection{Model Overview}

There are two main aspects of the catchment model used in this work. The first aspect concerns the description of a watershed in terms of hydrologically relevant characteristics; the second concerns the model use for representation of the physical processes of interest.

There have been several ways of representing a watershed; in the Stanford Watershed model [Crawford and Linsley, 1966] and the model by Hydrocomp Corporation [1972] the watershed is segmented according to differing soils, land use, and precipitation. Other models, such as the System Hydrologique European (SHE) model [Abbot et al., $1986 a, b]$, divide the watershed by using a rectangular grid. A third approach [Kibler and Woolhiser, 1970] involves dividing the watershed into cascading planes, where every planar segment has its own spatially uniform parameters, and rainfall varies temporally.

In this work the watershed area of Ralston Creek (approximately $7.5 \mathrm{~km}^{2}$ ) was delineated from a topographic base map [U.S. Department of Agriculture, 1964a] to highlight the main channel and its tributaries. The entire watershed was divided into subcatchments along the ridges of all major tributaries and minor tributaries using the topographic map of the watershed. The subcatchments were further divided into stream tubes along lines of the steepest slope. There are 210 stream tubes with an average area of $0.0465 \mathrm{~km}^{2}(4.7$ hectares) each. All watershed characteristics vary along a stream tube, and the stream tubes were further divided into stream tube segments according to their slope changes in a stream tube. The division was done in such a way that the properties of the basin, like slope, surface roughness, rainfall excess, length, width, erodibility, conservation practices, cropland management, and infiltration, are essentially spatially uniform within a stream tube segment. Figure 1 shows a schematic representation of the model logical units: stream tubes and stream tube segments. The length of the channel was measured between nodes. The length and width of each stream tube segment was then determined. The segments are not rectangular, but they were approximated as rectangles, preserving their area.

The runoff model used in the present study has components representing the various processes that continue runoff. First, the infiltration model derives the rainfall excess. This rainfall excess volume produces overland flow which is routed to the channel network by the overland flow routing model. The flow in the channel is routed to the outlet of the basin using a channel routing model. Both the overland and channel flow routing models are based on the kinematic wave theory. These models will be briefly outlined next to establish notation and to present some of the model assumptions. 


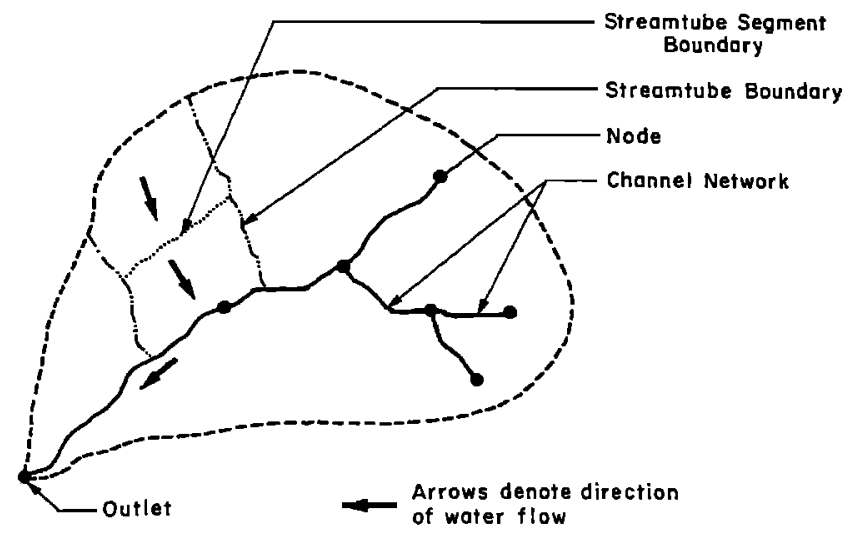

Fig. 1. Schematic representation of the model logical units.

\subsection{Infiltration Model}

The heart of any Hortonian (rainfall excess) rainfall-runoff model is the estimation of infiltration losses. Often, the performance of the entire modeling effort is dependent on the accuracy of this estimation. The rainfall loss components include losses such as interception and depression storage and infiltration; the last one having the largest influence on the volume of watershed runoff and rainfall-excess hyetograph.

For the purpose of this study it is assumed that the rainfall excess obtained by subtracting infiltration from precipitation directly contributes to surface runoff. Interception and depression storage mainly affect the runoff from the initial rainfall and are generally determined empirically without considering any time distribution (interception and depression storage may recover during rainfall due to evaporation). On the other hand, the infiltration process continues through all stages of rainfall, even after the rainfall ceases and, in general, is time variant. Once interception and depression storage are satisfied, and if evaporation is not considered, then rainfall excess can be determined by estimating the rate of infiltration.

Infiltration modeling was achieved by using the Soil Conservation Service (SCS) curve number approach. The bases for adopting the SCS model were as follows:

1. The SCS model parameters are defined with respect to soil type, land use, land treatment, and antecedent moisture index, all of which can be inferred from soil maps and reports easily available.

2. The SCS model parameters can be easily altered when man-made watershed modifications occur.

3. The SCS model is simple, computationally efficient, and easily adaptable to the mathematical formulation of a distributed model.

Although the shortcomings of the SCS approach are recognized, since the purpose of the study is not the modeling per se but the sensitivity (or more precisely uncertainty) analysis, the SCS model is deemed adequate. Actually, the use of the SCS procedure is another common aspect of this study and that by Wilson et al. [1979]. It makes the two studies directly comparable.

The parameters of the SCS model include the curve number which is related to the maximum potential retention $S$ and the antecedent moisture condition which defines a state of wetness of the soil based on the 5-day antecedent precipitation. Another parameter is the minimum infiltration rate for the soil. The parameters of the SCS model could be determined for an area by standard procedures, as outlined in the Hydrology Guide for Use in Watershed Planning [U.S. Department of Agriculture, 1964b.]

The SCS model was originally developed for predicting total volume of runoff from a gauged or ungauged watershed, where only total precipitation records are available. In this study the analysis required the application of the SCS model in finite time increments for the computation of the rainfall excess hyetographs.

An important issue is whether the SCS model can be used in finite time increments for rainfall-dependent infiltration rates. The original model assumes that if large time intervals are used, there are no excessive changes in the infiltration rate. The runoff volume varies insignificantly with the interval of computations. However, rainfall excess is sensitive to the time interval. Also, the kinematic flow equations are sensitive to the intensity of rainfall excess and the time distribution. The 1-hour rainfall excess patterns average out the effects of time distribution to a large extent, hence for improved predictions, 5-min rainfall and rainfall excess data were used. In order to do that, an extension of the SCS model was necessary. The initial loss rate, as obtained from the hourly data, was superimposed on the 5-min rainfall data, and the loss rate was adjusted so that the volume of runoff obtained is the same in the 5-min data as in the 1-hour data. Then, all observed 5-min rainfall that was less than the adjusted loss rate was set equal to zero. Our assumption is that the 1-hour runoff volume computed by the SCS model adequately represents the actual runoff. Both description and verification of the procedure are given by Kumar and Jain [1982]. For the details of the computational procedure refer to Jain et al. [1982] or Lakshmi [1989]. For tests of SCS with 15-min interval experimental data see Aron et al. [1977].

\subsection{Overland Flow Model}

In a distributed-parameter model, subsections of the watershed are modeled separately, and the various section outputs are combined to obtain watershed outflow hydrographs. In the model used the overland flows over the watershed segments and the flow down the stream are described by a one-dimensional kinematic wave model. The flow rate is related to the depth of flow by making use of Manning's equation. The values of Manning's roughness parameter $n$, for a variety of overland flow conditions, can be found in papers by Chow [1964], Crawford and Linsley [1966], or Novotny [1976].

The solution of the model equations was achieved by the modified second-order Lax-Wendroff explicit scheme with the appropriate boundary conditions. For the derivation of the numerical scheme equations and the discussion of the stability issues the interested reader is referred to Jain et al. [1982].

In the simulation experiment it was assumed that the segments are initially dry. Furthermore, the boundary conditions state that the outflow from one segment becomes inflow into the next segment. At the divide (first segment in the stream tube) there is zero inflow into the segment across the upper boundary, but for all other segments there is flow from one segment to another.

The kinematic wave model, which is described above, 
falls into the distributed-parameter model category. It uses equations from the distributed kinematic wave theory to develop overland flow segment hydrographs which are added and routed by methods of linear superposition and time lag routing. The fine geometric detail of the watershed descriptions used in the model allows good approximations with linear superposition and time lag routing. For details see Jain et al. [1982]. As an approximation to the Ralston Creek basin flow processes, the model is a good representation under the conditions of very intense quasi-stationary convective storms called Mesoscale Convective Complexes and for the spring rains when a frozen or partly frozen ground exists. At the same time it is recognized that the kinematic wave representation is not valid for the actual spatial flow dynamics under nonuniform infiltration rate conditions and highly variable microtopography. However, the available data allows for the model assessment only at the basin scale.

Another reason for the good performance of the kinematic wave model applied to the Ralston Creek basin is the high variability of the physiographic characteristics of the basin, the slopes in particular. The difference of elevation between the outlet and the highest point in the basin is about $50 \mathrm{~m}$, and the average slope for the segments selected is 0.1 , ranging from the minimum of 0.007 to the maximum of 0.7 . Again, lack of appropriate data does not allow for detailed (segment scale) investigations of the applicability condition of the kinematic wave equations. Such condition can be expressed [Ponce, 1989] in terms of time-of-rise of the inflow hydrograph, segment bottom slope, average velocity, and average water depth. It can be easily shown that for timeof-rise of the order of minutes, average velocity of the order of centimeters per second, and average depth of 1-2 centimeters the applicability condition is met even for slopes as low as 0.007 .

\subsection{Channel Model}

Using the kinematic wave approximation, and assuming invariant roughness and slope, the channel discharge may be expressed as

$$
Q_{s}=f(A)
$$

where $Q_{s}$ is the channel flow, and $A$ is cross-sectional area. The function $f(A)$ is, in general, nonlinear. is

The continuity equation between the nodes of the channel

$$
\frac{\partial A}{\partial t}+\frac{\partial Q}{\partial x}=0
$$

thus by substituting (1) into (2) one obtains

$$
\frac{\partial A}{\partial t}+\frac{\partial Q}{\partial A} \frac{\partial A}{\partial x}=\frac{\partial A}{\partial t}+f^{\prime}(A) \frac{\partial A}{\partial x}=0
$$

where $f^{\prime}(A)$ is the slope of the area-discharge curve. Again, the above equation can be solved by the Lax-Wendroff explicit scheme.

Stream cross sections were determined approximately every $30 \mathrm{~m}$ along the main channel, and the location of tributaries was determined from 2-ft contour maps. Although inaccuracy in cross sections can give rise to errors in hydrograph shape and timing, this is not a problem here since in this study we effectively model a hypothetical catchment with characteristics very closely resembling those of Ralston Creek.

Manning's $n$ values for the main channel flow were provided by the United States Geological Survey; since Manning's $n$ was not available for tributaries, it was estimated from a given channel of similar cross sections on the main channels.

\section{The Monte Carlo Simulation Experiment}

\subsection{Rainfall Model}

Because of the lack of detailed data it was not possible to perform sensitivity analysis for the Ralston Creek basin based on actual observations. Instead, a stochastic spacetime rainfall model was used to generate the input data. The model selected was that proposed by Waymire et al. [1984]. The model, also called the WGR model, conceptualizes mesoscale rainfall fields as clusters of cells defined with life span, velocity, and rainfall intensity. By accounting for rainfall contributions from each rain cell, one can construct a rainfall field with a realistic appearance and statistics in the form of a space-time covariance function resembling that of observed rainfall.

There are several parameters in the rainfall model, and by changing them appropriately one could generate different rainfall climatic regimes, as was done by Valdes et al. [1985]. For a full description of the model an interested reader is referred to papers by Waymire et al. [1984] and Valdes et al. [1985, 1990].

Since the model was developed in terms of instantaneous rainfall rate, in principle it was possible to generate both hourly as well as 5 -min point rainfall fields which were then sampled by simulated rain gauges imposed on the Ralston Creek watershed. The model used the parameter values closely corresponding to the climate 1 case, as given by Valdes et al. [1985]. Climate 1 parameters refer to rather significant rainfall. This choice was made because our interest was in flood events and not in the whole gamut of hydrological conditions.

It must be emphasized at this point that there was no attempt made to calibrate the WGR model to Iowa's rainfall regime. As pointed out earlier, the intention of the authors was to gain more experience with the distributed model presented herein, investigate its sensitivity with respect to the input sampling errors, and compare its performance to a simple lumped model. It was not their objective to study the runoff characteristics of Ralston Creek basin, as such a study would certainly require the rainfall data appropriate for this part of Iowa.

To achieve these objectives a Monte Carlo experiment was performed in which several scenarios of model rainfall input were examined. In the numerical simulations the parameters were constant over the sample size of 100 storms (realizations) affecting the basin.

\subsection{Lumped Model}

The lumped model used in this study is based on the unit hydrograph concept. The hourly unit hydrograph was derived for the basin not from an observed record but through simulation. Following the definition of the hourly unit hydrograph [e.g., Bras, 1990], a unit depth rainfall excess (1 in $(2.5 \mathrm{~cm})$ ) was uniformly distributed over the whole basin and 


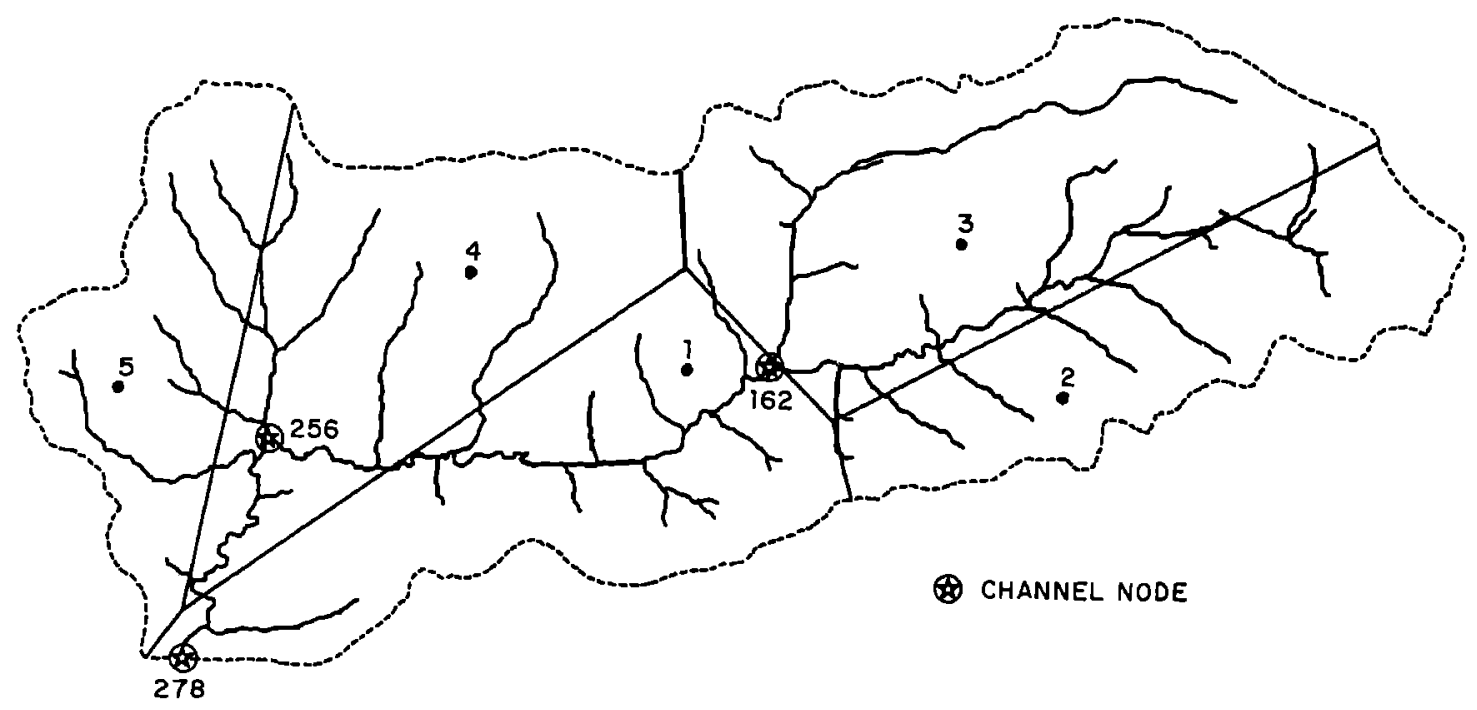

Fig. 2. Schematic map of the Ralston Creek basin. Indicated are the locations of the actual rain gauges, the corresponding Thessien polygons, and three nodes at which the computations of the hydrographs were monitored.

routed to the outlet by the distributed model. That way, the variability of basin land use and other physiographic characteristics was taken into account. The resultant hydrograph was subsequently used as the unit hydrograph. The hourly unit hydrograph was used with rainfall sampled as hourly accumulations at a single gauge centrally located in the basin. In the application of this approach, in order to use the SCS model for determination of rainfall excess, the basin characteristics had to be represented by spatially averaged values. This averaging was done objectively using weights based on the area of the particular segments.

The unit hydrograph derived in the above-described way represents the best possible one. This is because all the assumptions concerning effective rainfall, implicit in the unit hydrograph concept, were followed exactly. It must be emphasized, though, that the assumption of linearity of the basin was invoked only in the computations of the storm hydrographs and not in its derivation.

\subsection{Experimental Setup}

The experiment was designed to highlight the effect of input uncertainty as well as the effects of temporal and spatial sampling. In addition, the performance of a lumped model was compared against that of a distributed model.

The true response or "ground truth" was chosen to be the response generated by the distributed model with rainfall input from 87 gauges (for dense spatial sampling, no interpolations involved) and a 5 -min sampling interval (case 1 ). This density is almost 12 gauges per $\mathrm{km}^{2}$.

Another case is only one gauge located in the center of the catchment and hourly rainfall input (case 2). This corresponds to a lumped input case.

For the distributed model we also chose a rain gauge network of five gauges with Thiessen polygon interpolation (case 3) and 87 gauges with hourly rainfall inputs (case 4). Of these the latter provided us with a measure of the effects of temporal sampling. The case of five gauges was selected since in the Ralston Creek basin there is (although not active anymore, Danushkodi [1974]) such a network of rain gauges.
Figure 2 shows the location of these five gauges in the Ralston Creek watershed.

The lumped model (case 5) uses the rainfall input sampled as in case 2. The layout of the Monte Carlo experiment is outlined in the flow diagram of Figure 3 and in Table 1.

The five cases were run along with the stochastic rainfall model, and the catchment responses at the three locations, nodes 162, 256, and 278 (Figure 2), were stored and then

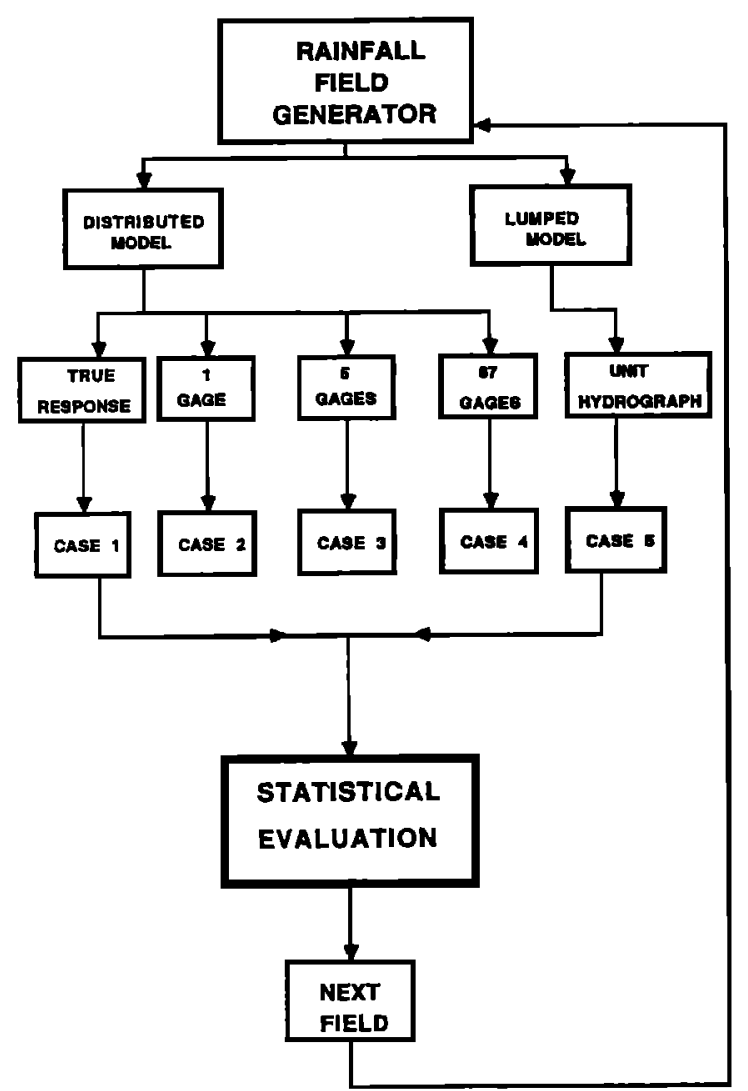

Fig. 3. Schematic diagram of the Monte Carlo experiment. 
TABLE 1. Listing of Scenarios Investigated in the Monte Carlo Experiment

\begin{tabular}{|c|c|c|c|}
\hline Case & $\begin{array}{l}\text { Number of } \\
\text { Gauges }\end{array}$ & $\begin{array}{l}\text { Input } \\
\text { Resolution }\end{array}$ & Location/Comments \\
\hline 1 & 87 & $5 \mathrm{~min}$ & $\begin{array}{l}\text { catchment divided into } 87 \text { homogeneous (based on land use, slope, } \\
\text { roughness) areas with one gauge placed in the center of each; } \\
\text { assumed to be the true response }\end{array}$ \\
\hline 2 & 1 & 1hour & $\begin{array}{l}\text { placed approximately in the center of the catchment; represents the } \\
\text { lumped input case }\end{array}$ \\
\hline 3 & 5 & 1hour & $\begin{array}{l}\text { same locations as of the original gauges [Jain, 1982]; Thessien } \\
\text { polygons used to interpolate }\end{array}$ \\
\hline 4 & 87 & ihour & same as case 1 \\
\hline 5 & 1 & lhour & same as case 2 \\
\hline
\end{tabular}

analyzed statistically (for case 5 the hydrograph was obtained only for the outlet).

\subsection{Comparison Criteria}

To examine how cases $2,3,4$, and 5 compare with case 1 (which was considered as the "ground truth") a comparison was made between corresponding hydrographs (time series) obtained in cases 1 and 2,1 and 3,1 and 4, and 1 and 5 .

The selected comparison criteria were (1) zero-lag cross correlation between corresponding discharges at each of the three nodes, (2) maximum absolute difference between the time series of corresponding discharges (for each event and for each node), (3) mean absolute difference in corresponding discharges, and (4) root mean square of the difference in corresponding discharges.

Individual hydrographs at each node were analyzed in terms of (1) peak discharge, (2) time to peak (the peak being the first observed peak), and (3) number of peaks.

\section{Results}

The power of the Monte Carlo approach is also its weakness. The study explained in the previous section yielded some interesting results, but the abundance of generated data created problems of their digestion, analysis, and finally, presentation. Here, for the sake of brevity and clarity, only a subset of generated results is presented. The

TABLE 2. Parameter Values Used for the WGR Model

\begin{tabular}{lr}
\hline \multicolumn{1}{c}{ Parameter } & Value \\
\hline Strom duration, hours & 5.0 \\
Rainfall sampling interval, minutes & 5.0 \\
Rainband radius, $\mathrm{km}$ & 70.0 \\
Cluster potential center radius, $\mathrm{km}$ & 30.0 \\
Average number of cluster potential centers in & 15.0 \\
rainband per unit area, $\mathrm{km}^{-2}$ & \\
Cluster spread factor, $x$ axis, $\mathrm{km}$ & 15.0 \\
Cluster spread factor, $y$ axis, $\mathrm{km}$ & 15.0 \\
Cellular birth rate, $\mathrm{h}^{-1}$ & 2.3 \\
Average number of cells per cluster potential & 15.0 \\
center & \\
Average storm velocity, $x$ axis, $\mathrm{km} \mathrm{h}^{-1}$ & 8.0 \\
Average storm velocity, $y$ axis, $\mathrm{km}^{-1} \mathrm{~h}^{-1}$ & 0.0 \\
Attenuation coefficient in time, $\mathrm{h}^{-1}$ & 5.1 \\
Attenuation coefficient in space, $\mathrm{km}^{-1}$ & 5.0 \\
Maximum intensity, mm $\mathrm{h}^{-1}$ & 200.0 \\
Cell life, hours & 0.9 \\
Cell radius, $\mathrm{km}$ & 15.0 \\
Length, $x$ axis, $\mathrm{km}$ & 20.0 \\
Length, $y$ axis, $\mathrm{km}$ & 20.0 \\
\hline
\end{tabular}

selected sample is based on 100 realizations, with only the distribution of the flood peaks being based on 1000 realizations. This sample is representative of other obtained results in that trends similar to the ones presented herein were observed. For more detailed results the interested reader is referred to Lakshmi [1989] where all the computed statistics are discussed.

Since the intention of the study was to evaluate the effects of spatial heterogeneity of the basin and the rainfall input, the first issue faced was whether the WGR model, with the given set of parameters (Table 2), is capable of generating

\section{Excess rain coverage (in percent)}

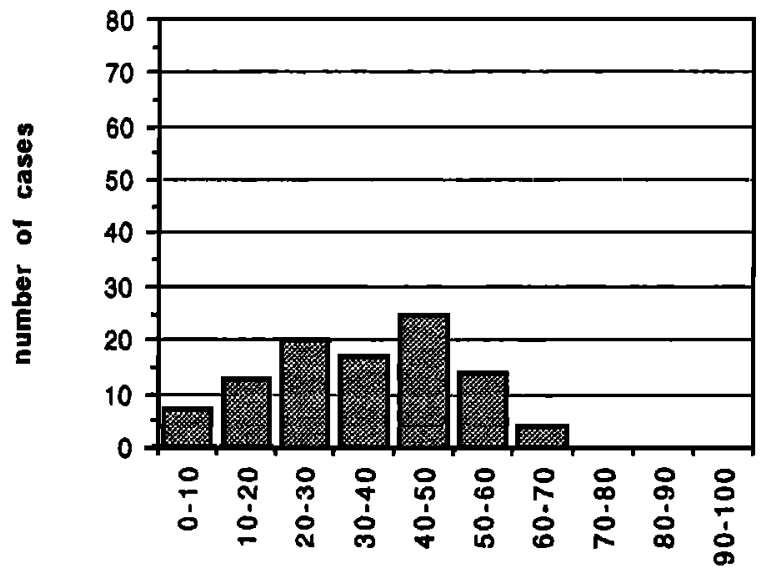

Total rain coverage (in percent)

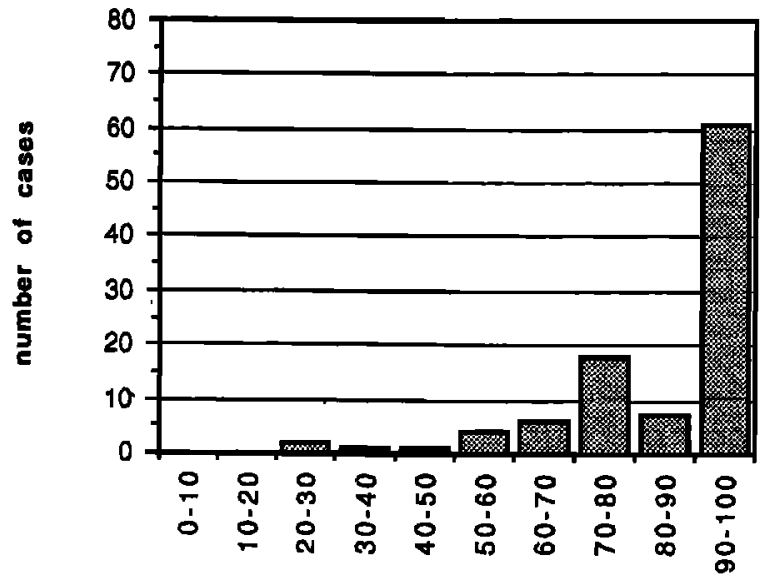

Fig. 4. Percent coverage of the basin by rainfall and by rainfall excess. The results are based on 100 realizations. 


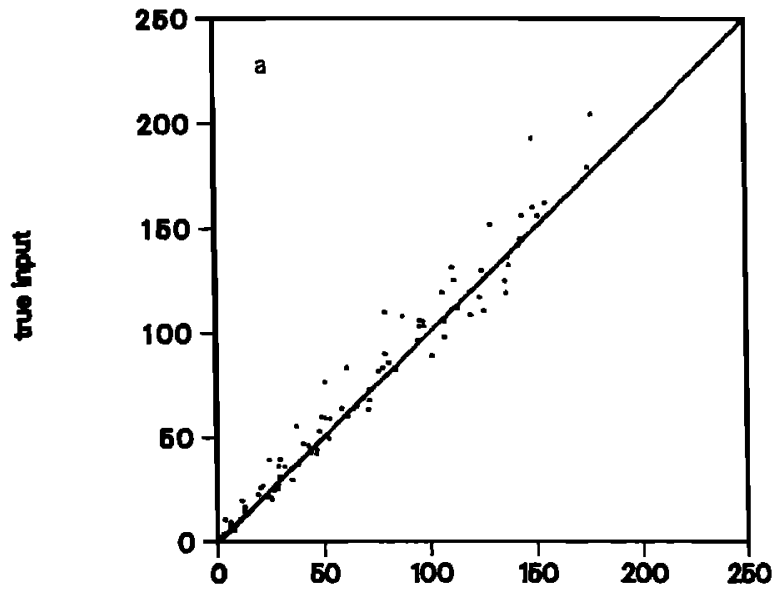

poak from ainglo gage

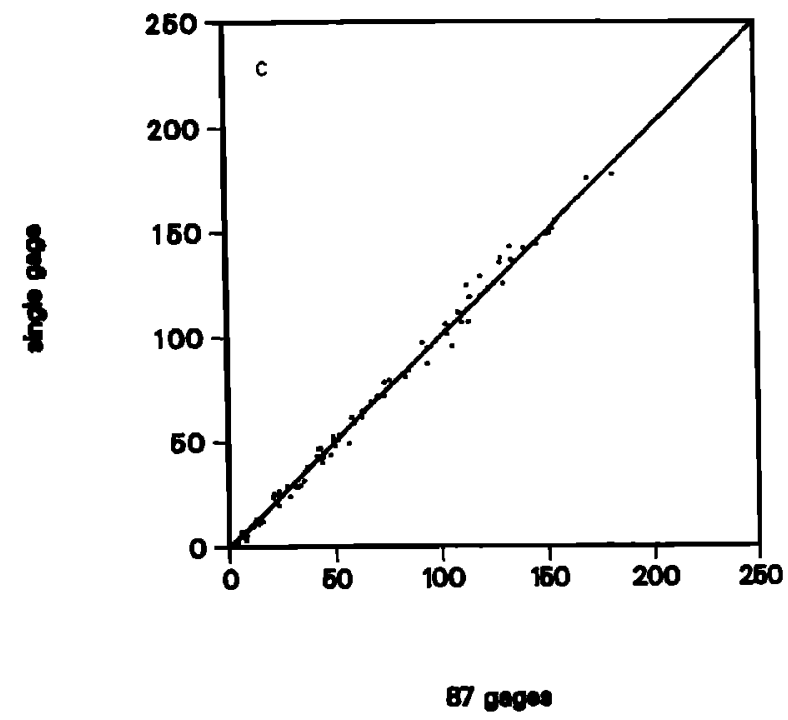

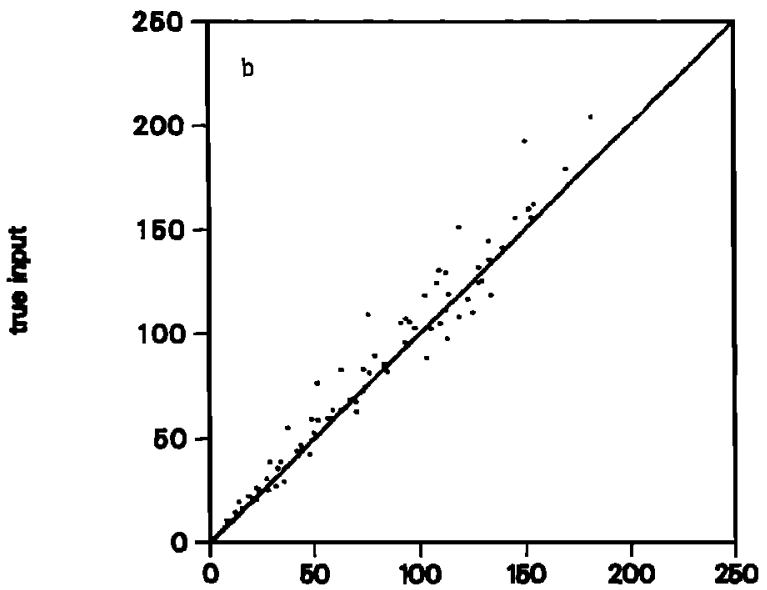

peak 87 gages

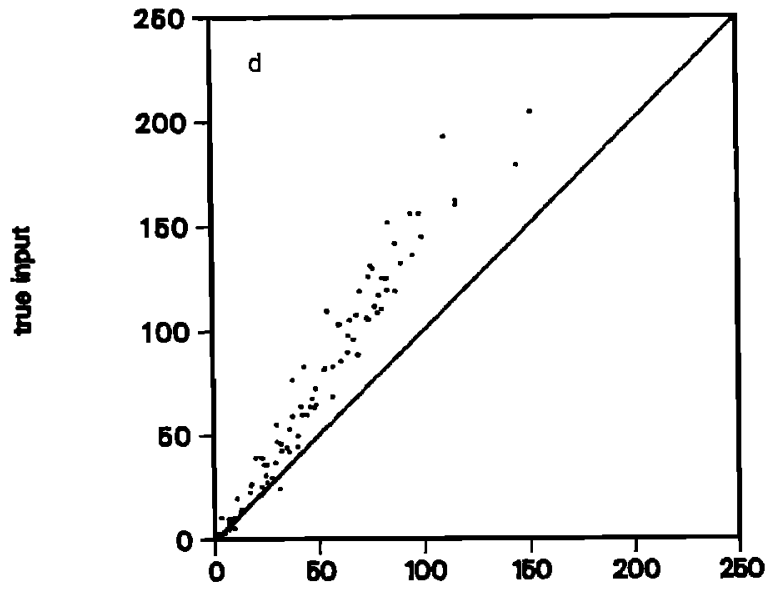

poek from lumped model

Fig. 5. Results of the Monte Carlo experiment. Hydrograph peak estimation for (a) cases 1 and 2, (b) cases 1 and 4, $(c)$ cases 2 and 4, (d) cases 1 and 5 . Peak flows are given in $\mathrm{m}^{3} \mathrm{~s}^{-1}$.

distinct enough patterns of runoff at the scale of a small basin like Ralston Creek. The answer to this question is positive as indicated by -the results of Figure 4. Figure 4 shows the variation of percentage areal coverage by the total rainfall (bottom) and the rainfall excess (top) for a set of 100 cases that were examined. Although the percent coverage of the basin by rainfall was nearly uniform, the percent coverage by rainfall excess shows highly variable behavior.

Several statistics were computed to characterize the obtained results. One of them was the correlation coefficient between the hydrograph obtained using the investigated scenarios and the "true" hydrograph. This statistic can be compared for each realization separately.

The unit hydrograph based method had a highest correlation (between the time series of discharges obtained by using the unit hydrograph based method and the ground truth method) of 0.989 . In several other cases the unit hydrograph matches well with the true response in terms of correlation. This agrees with the results of investigations by Williams et al. [1980], who showed a close agreement between the hydrographs obtained by unit hydrograph simulations and those from a physically based model. The data for their physical model were derived from catchment details, while the unit hydrograph was derived from measured rainfall and streamflows. The lowest absolute correlation for the unit hydrograph was 0 . It corresponds to a case of zero rainfall excess computed, based on observed rainfall at a single gauge which happened to completely "miss" the storm. The result is a zero discharge runoff computed at the outlet of the basin. Also, the averaging of the basin properties for use with the lumped model leads, in some cases, to zero surface runoff. The overall performance (averaged over 100 cases) of the unit hydrograph based model was not very good.

For the one-gauge case (case 2), the highest correlation observed was 0.995 , and the lowest is 0.431 . In the fivegauge setup the highest correlation observed is 0.997 , and the lowest is 0.755 . Visual inspection of the hydrographs (not shown here) revealed that low correlations are often caused by a shift in time. However, a full analysis of the time correlation function was not attempted. The high correlation 

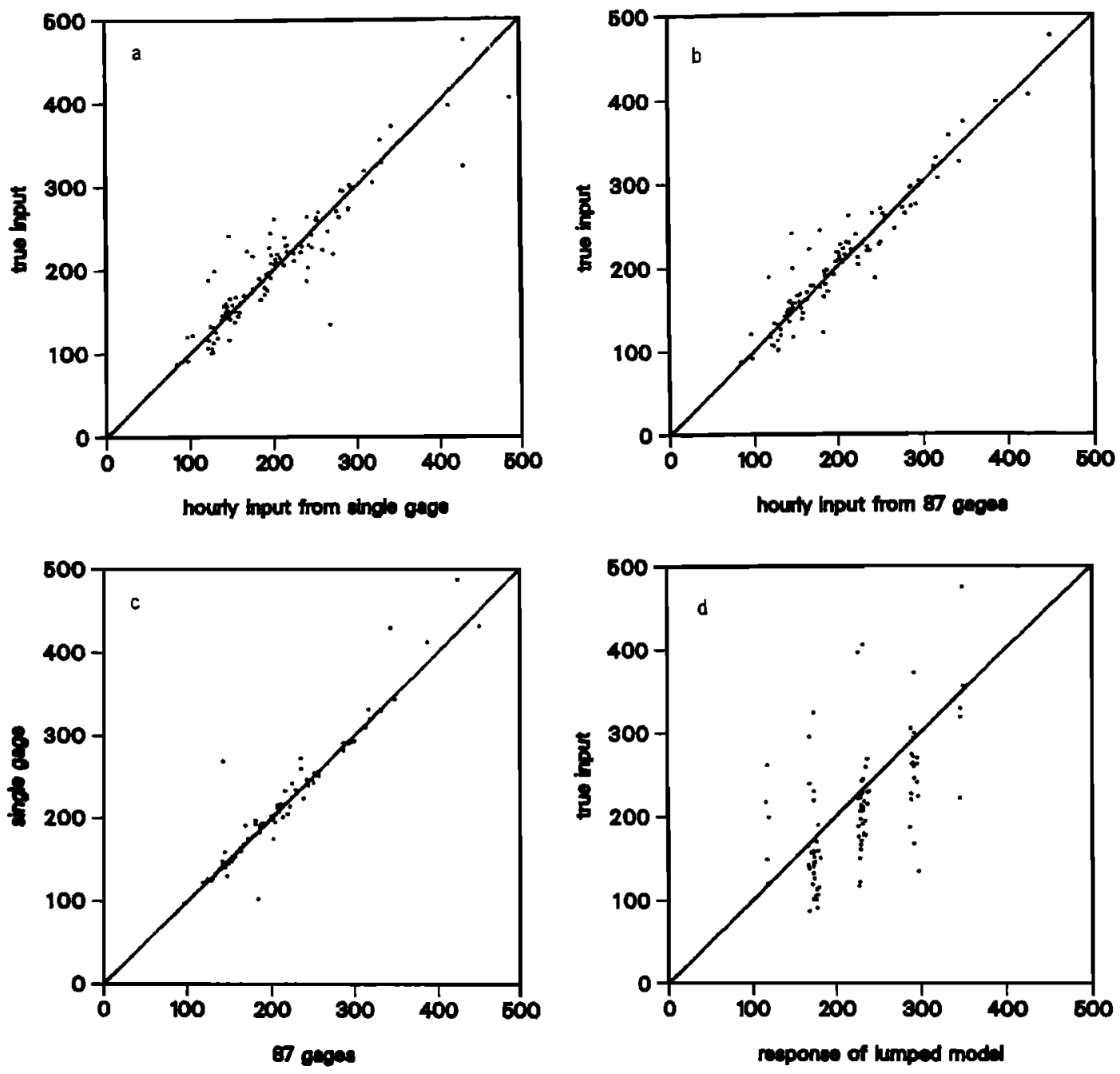

Fig. 6. Results of the Monte Carlo experiment. Hydrograph time-to-peak estimation for $(a)$ cases 1 and 2, $(b)$ cases 1 and $4,(c)$ cases 2 and $4,(d)$ cases 1 and 5 . Time-to-peaks are given in minutes.

of 0.997 and a low of 0.833 is observed for the 87 -gauge setup. It should be noted that the low correlation keeps on increasing as the number of gauges increase. The high correlation also keeps on increasing. This clearly indicates an increased accuracy as the number of gauges increases. The average of the correlations (for 100 storms) also follows a similar trend. The average correlation is 0.779 for the unit hydrograph, 0.927 for the one-gauge case, 0.936 for the five-gauge case, and 0.944 for the 87 -gauge setup.

The increase in accuracy is not markedly different for the gauge cases with numbers 1,5 , and 87 . This is what one would expect by intuition that, for a small catchment, one gauge should suffice. The standard deviation of the correlations are 0.291 for the unit hydrograph, 0.150 for the onegauge case, 0.138 for the five-gauge case, and 0.138 for the 87-gauge setup.

Similar conclusions can be reached by analysis of peak discharge and time-to-peak. Figures 5 and 6, respectively, show scatter plots of the results of the analysis of the hydrograph peaks and the hydrograph time-to-peak. The comparison of the true response and the 87-gauge with hourly input case (Figure $5 b$ ) is indicative of the effect of temporal sampling resolution. The comparison of one gauge (case 2) and 87 gauges (case 4) in Figure $5 c$ indicates the effects of spatial sampling. The inspection of Figures 5 and 6 leads to the conclusion that the effect of varying time resolution is more dominant than the spatial undersampling for the $7.5 \mathrm{~km}^{2}$ basin under study. This seems reasonable considering the small size of the basin investigated. Nevertheless, both effects are not that significant, and the performance of the distributed model, based on hourly rainfall input and a few gauges, is quite good. The results support the findings by Hamlin [1983], who reported errors of the order of $100 \%$ in the peak discharge and $73 \%$ in the time-to-peak for his studies involving reduced gauge networks for runoff prediction. It is pointed out that our generated rainfall fields were sampled without accounting for rain gauges measurement errors.

The performance of the lumped model is not as good. It displays a significant bias toward underestimation (see Figure $5 d$ ). The unit hydrograph was derived under the most favorable conditions, that is, meeting all the assumptions of the underlying theory. The lumped model's inability to reproduce the hydrographs generated by the distributed model clearly is due to the nonlinear nature of the basin response. The presence of bands of points separated by 


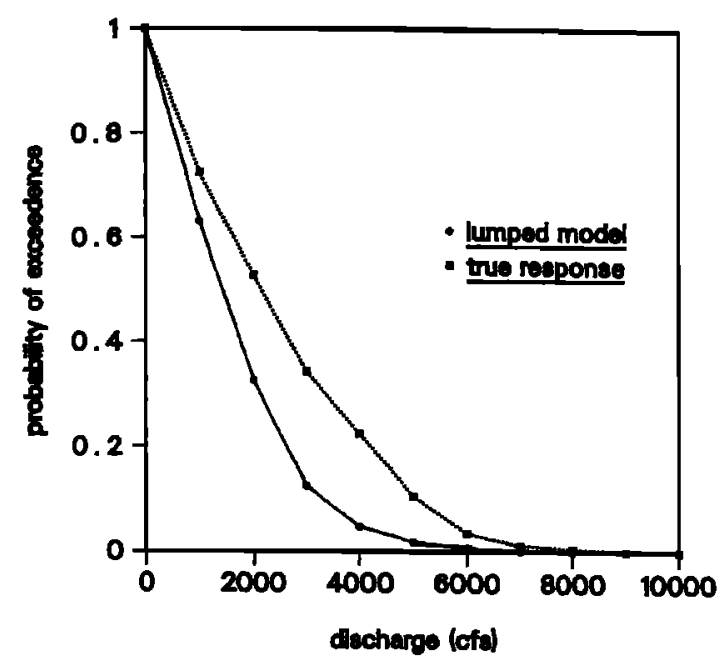

Fig. 7. Flood peak frequency distribution for the true response and the lumped model. The result is based on 1000 realizations.

about $60 \mathrm{~min}$ in Figure $6 d$ is because of the fact that the unit hydrograph was derived using one unit of rainfall excess over a period of 1 hour.

Perhaps the most important result of this study is given in Figure 7. Figure 7 shows the peak discharge-frequency curves. Two peak discharge frequency distributions are presented, one for the distributed model and one for the lumped model. It is obvious that severe underestimation of the tail portion of the frequency curve results in the use of the lumped model. Thus application of a simple lumped model for the design of hydraulic structures is not recommended, as it may lead to underdesign with respect to extreme floods. However, as pointed out earlier, the performance of the lumped model was not optimized, and the potential source of suboptimal results was the lumped representation of the basin characteristics which were obtained subjectively. On the other hand, all other assumptions of the unit hydrograph theory concerning the input were met exactly, which is not always possible in the practical use of this method. If therefore the two effects offset each other, then the results presented herein are representative.

\section{Conclusions and Final Remarks}

The investigations of the sensitivity of a distributed parameter model with respect to the sampling density of a synthetic rain gauge network and the temporal resolution of the rainfall data has shown the considerable effect of decreased temporal resolution. The effect of varying spatial sampling is not as prominent, but in some cases it is also significant. When a lumped model is used instead of the distributed model, a strong bias develops in flood peak simulations. In addition to the bias there were several cases where the distributed model produced multiple peaks which the lumped model was unable to reproduce. Lumping of the input and the variability of the spatial basin characteristics are responsible for such cases.

The Monte Carlo approach could be extended to study problems of appropriate scale selection and data resolution for real-time hydrologic forecasting. In order to facilitate such studies a model of the type described herein should be complemented by a geographic information system (GIS) with digital elevation models [Moore, 1985] and remotely sensed data. The problem of optimal resolution can be studied easily with distributed models based on a rectangular grid. It is more difficult with the variable-shape geometry of our model, but there are techniques which can handle such formulation [Moore and Kinnell, 1987]. The problem of radar-rainfall sampling effect is reported by Chandrasekar et al. [1990].

It is also conceivable to think that the Monte Carlo framework could constitute the basis for future design studies. Instead of constructing highly simplistic design storms, one could use a locally fitted stochastic (or other type) space-time model of rainfall to provide the required input and a distributed model adequate for the problem at hand and investigate the uncertainty and/or reliability aspects using Monte Carlo simulations. Modern GIS-type data basis could provide interfacing with a bank of studied alternatives. We think that such methodology, though computationally intensive, would be easily interpretable and thus appealing.

Acknowledgments. Research leading to this paper was partially supported by grants from the National Science Foundation under the Presidential Young Investigator Award CES-8657526, the Cold Regions Research and Engineering Laboratory, United States Army Corps of Engineers, under contract DACA89-87-K-004, and the University of Iowa College of Engineering Block Allocation Program. The authors are grateful for this support. Also, discussions with Forrest M. Holly, Jr., and Charles Obled are acknowledged and appreciated. The comments by two anonymous reviewers and Stephen Burges lead to greatly improved readability of the original manuscript. Apollo DN10000 supermini computer of the Computational Laboratory for Hydrometeorology and Water Resources, The University of lowa, was used to perform the computations.

\section{REFERENCES}

Abbott, M. B., J. C. Bathurst, J. A. Cunge, P. E. O'Connel, and J. Rasmussen, An introduction to the European Hydrologic System-Systeme Hydrologique European, "SHE", 1, History and philosophy of a physically-based distributed modelling system, $J$. Hydrol., 87, 45-59, 1986a.

Abbott, M. B., J. C. Bathurst, J. A. Cunge, P. E. O'Connel, and J. Rasmussen, An introduction to the European Hydrologic System-Systeme Hydrologique European, "SHE", 2, Structure of a physically-based distributed modelling system, J. Hydrol., $87,60-77,1986 b$.

Aron, G., A. C. Miller, Jr., and D. F. Lakatos, Infiltration formula based on SCS curve number, J. Irrig. Drain. Eng., IR4, 419-427, 1977.

Beven, K., Distributed models, in Hydrological Forecasting, edited by M. G. Anderson and T. P. Burt, pp. 405-435, John Wiley, New York, 1985.

Beven, K., Changing ideas in hydrology-the case of physicallybased models, J. Hydrol., 105, 157-172, 1989.

Beven, K., and P. E. O'Connell, On the role of distributed models in hydrology, Rep. 81, Inst. of Hydrol., Wallingford, U.K., 1982.

Binley, A., J. Elgy, and K. Beven, A physically based model of heterogeneous hillslopes, 1, Runoff production, Water Resour. Res., 25(6), 1219-1226, $1989 a$.

Binley, A., J. Elgy, and K. Beven, A physically based model of heterogeneous hillslopes, 2, Effective hydraulic conductivities, Water Resour. Res., 25(6), 1227-1226, 1989 b.

Bras, R. L., Hydrology-An Introduction to Hydrologic Science, Addison-Wesley, Reading, Mass., 1990.

Bras, R. L., and I. Rodriguez-Iturbe, Rainfall generation: A nonstationary time-varying multidimensional model, Water Resour. Res., 12(3), 450-456, 1976.

Chandrasekar, V., W. F. Krajewski, and V. Lakshmi, A Monte Carlo study of radar-rainfall sampling for hydrologic applications, 
paper presented at the Conference on Hydrometeorology, Am. Meteorol Soc., Kananaski, Canada, 1990.

Chow, V. T. (ed.), Handbook of Applied Hydrology, McGraw-Hill, New York, 1964.

Collinge, V. K., and C. Kirby (Eds.), Weather Radar and Flood Forecasting, John Wiley, New York, 1986.

Crawford, N. H., and R. K. Linsley, Digital Simulation in Hydrology-Stanford Watershed Model 4, Tech. Rep. 39, Dep. of Civ. Eng., Stanford Univ., Calif., 1966.

Danushkodi, V., 1972 Ralston Creek project (North and South branches) with rainfall, runoff and groundwater data, Iowa Inst. of Hydraul. Res., lowa City, 1974.

Dawdy, D. R., and J. M. Bergmann, Effect of rainfall variability on streamflow simulation, Water Resour. Res., 5, 958-966, 1969.

Field, W. G., and B. J. Williams, A generalized kinematic catchment model, Water Resour. Res., 23(8), 1675-1681, 1987.

Hamlin, M. J., The significance of rainfall in the study of hydrological processes at basin scale, J. Hydrol., 65, 73-94, 1983.

Hudlow, M. D., Technological developments in real-time operational hydrological forecasting in the United States, J. Hydrol., $102,69-92,1988$.

Hydrocomp Corporation, Hydrocomp Simulation Programming, Operations Manual, 2nd ed., Palo Alto Calif. 1972.

Ishizaki K., F. Yoshino, K. Takeuch, and A. Yoo, A study on short-term rainfall prediction by radar raingage, in New Directions for Surface Water Modeling, edited by M. L. Kavvas, 3-12, IAHS Publ., 181, 1989.

Jain S. C., S. Kumar, G. Whelan, and T. E. Croley, IIHR distributed parameter watershed model, IIHR Rep. 244, Iowa Inst. of Hydraul. Res., Iowa City, 1982.

Kibler, D. F., and D. A. Woolhiser, The kinematic cascade as a hydrologic model, Hydrol. Pap. 39, Colo. State Univ., Fort Collins, 1970.

Kumar, S., and S. C. Jain, Application of SCS Infiltration Model, Water Resour. Bull., 18(3), 503-508, 1982.

Lakshmi, V., Investigation of the effects of rainfall input variability using a distributed parameter catchment model, M.S. thesis, Dep. of Civ. and Environ. Eng., Univ. of Iowa, Iowa City, 1989.

Moore, I. D., Kinematic overland flow: Generalization of Rose's approximate solution, J. Hydrol., 82, 233-245, 1985.

Moore, I. D., and P. I. A. Kinnell, Kinematic overland flow: Generalization of Rose's approximate solution, II, J. Hydrol., 92, 351-362, 1987

Novotny, V., Hydrologic and hydraulic conceptual models applicable to overland and river transport modelling, Water Resour. Cent., Univ. of Wisc., Madison, 1976.

Ponce, V. M., Engineering Hydrology-Principles and Practices, Prentice-Hall, Englewood Cliffs, N. J., 1989.

Rose, C. W., J.-Y. Parlange, G. C. Snyder, S. Y. Cambell, and D. A. Barry, Kinematic flow approximation to runoff on a plane: An approximate analytic solution, $J$. Hydrol., 62, 363-369, 1983.

Sharma, M. L., R. J. Luxmoore, R. DeAngelis, R. C. Ward, and G. T. Yeh, Subsurface water flow simulated for hillslopes with spatially dependent soil hydraulic characteristics, Water Resour. Res., 28(8), 1523-1530, 1987.

Smith, R. E., and R. H. N. Hebbert, A Monte Carlo analysis of the hydrologic effects of spatial variability of infiltration, Water Resour. Res., 15(2), 419-429, 1979.

Sunada, K., and T. F. Hong, Effects of slope conditions on direct runoff characteristics by the interflow and the overland flow model, J. Hydrol., 102, 323-334, 1988.

Takasao, T., and M. Shiiba, Incorporation of the effect of concentration of flow into the kinematic wave equations and its applications to runoff system lumping, $\boldsymbol{J}$. Hydrol., 102, 301-322, 1988.

Troutman, B. M., Runoff prediction errors and bias in parameter estimation induced by spatial variability of precipitation, Water Resour. Res., 19(3), 791-810, 1983.

U.S. Department of Agriculture, Topographic map of Ralston Creek watershed, Soil and Water Conserv. Div., Agric. Res. Serv., Columbia, Mo., 1964a.

U.S. Department of Agriculture, Hydrology guide for use in watershed planning, in Hydrology Natl. Eng. Handb., Sect. 4, Suppl. A, Soil Conserv. Serv., Washington, D. C., $1964 b$.

Valdes, J., I. Rodriguez-Iturbe, and V. K. Gupta, Approximations of temporal rainfall from a multidimensional model, Water Resour. Res., 2I(8), 1259-1270, 1985.

Valdes, J. B., S. Nakamoto, S. S. P. Shen, and G. R. North, Estimation of multidimensional precipitation parameters by areal estimates of oceanic rainfall, J. Geophys. Res., 95(D3), 21012112, 1990.

Waymire, E., V. K. Gupta, and I. Rodriguez-Iturbe, A spectral theory of rainfall at the meso- $\beta$ scale, Water Resour. Res., 20(10), 1453-1465, 1984.

Williams, D. R., R. J. Cameron, and G. P. Evans, TRRL and unit hydrograph simulation compared with measurements in an urban catchment, J. Hydrol. 48, 63-70, 1980.

Wilson, C. B., J. B. Valdes, and I. Rodriguez-Iturbe, On the influence of the spatial distribution of rainfall on storm runoff, Water Resour. Res., 15(2), 321-328, 1979.

Woolhiser, D. A., and D. C. Goodrich, Effect of storm rainfall intensity patterns on surface runoff, J. Hydrol., 102, 335-354, 1988.

Wood, E. F., M. Sivapalan, K. Beven, and L. Band, Effects of spatial variability and scale with implications to hydrologic modeling, J. Hydrol., 102, 29-48, 1988.

Wooding, R. A., A hydraulic model for the catchment-stream problem, I, Kinematic-wave theory, J. Hydrol., 3, 254-267, 1965.

K. P. Georgakakos, S. C. Jain, W. F. Krajewski, and V. Lakshmi, Department of Civil and Environmental Engineering and Iowa Institute of Hydraulic Research, University of Iowa, Iowa City, IA 52242.

(Received April 24, 1990;

revised August 30, 1990;

accepted September 6, 1990.) 